\title{
Chemotaxonomic studies on Tragia involucrata Linn.
}

\author{
Muthuraman MEENAKSHI SUNDARAM ${ }^{1^{*}}$, Raghunath DEEPTHI ${ }^{1}$, Dorairaj \\ SUDARSANAM $^{2}$, Rengaraju SIVASUBRAMANIAN ${ }^{1}$ and Pemaiah BRINDHA ${ }^{3}$ \\ ${ }^{1}$ Department of Biotechnology, Srimad Andavan Arts and Science College, No.7, Nelson Road, \\ T.V.Koil, Trichy-620 005, Tamil Nadu, India. \\ ${ }^{2}$ Department of Advanced Zoology \& Biotechnology, School of Genomics, Loyola College, \\ Nungambakkam, Chennai-600 034, Tamil Nadu, India. \\ ${ }^{3}$ Dean, Biosciences, Srimad Andavan Arts and Science College, No.7, Nelson Road, T.V. Koil, \\ Trichy-620 005, TamilNadu, India. \\ * Corresponding author, E-mail: msundar77@yahoo.com; Tel: +91-9894475375
}

\begin{abstract}
In the present work a common plant in and around trichy, botanically equated as Tragia involucrata Linn belonging to the family Euphorbiaceae, has been studied from chemotaxonomic point of view. The study explained the identification and characterization of the compounds isolated from this plant. The chloroform extract of T. involucrata L was subjected to FT-IR and GC-MS to identify the compounds present in it. The compounds identified were Ar- Tumerone; 9, 10 Anthracenedione 1,8-dihydroxy-3-methyl; Friedelane-3-one. The therapeutic potentials of the active principles identified were already assessed. Ar-Tumerone was already reported from Curcuma longa $\mathrm{L}$ and the antibacterial and wound healing activity of this compound was well established. Chemistry of $T$. involucrata L reported in this present work can contribute significantly in providing chemical evidence in support of its inclusion in the family Euphorbiaceae and assigning the position to the genus Tragia.
\end{abstract}

(c) 2009 International Formulae Group. All rights reserved.

Keywords: Tragia involucrata, Chemotaxonomic studies, Ar-Tumerone.

\section{INTRODUCTION}

The search for natural products to cure diseases represents an area of great interest in which plants have been the important source (Meyer and Afoloyan, 1996). Plant materials play a major role in primary health care as therapeutic remedies in many developing countries (Zakaria, 1991). In the present work, a common plant in and around trichy popularly called as "kaanchori" botanically equated as Tragia involucrata Linn was selected and studied from chemotaxonomic point of view. T. involucrata Linn (Euphorbiaceae) is a perennial evergreen hispid herb with scattered stinging hairs distributed all over India.
The plant is traditionally used in pruritic skin eruptions, vomiting, guinea worms and gastropathy. The aqueous extracts of the leaves of $T$. involucrata was also screened for antimicrobial and anti inflammatory activity and methanol extract was reported to possess wound healing property (Ramar et al., 2006a, 2006b). Analgesic activity of the whole plant (Alimuzzaman et al., 2005), antiinflammatory activity of methanolic fraction of root extract of T. involucrata (Dhara et al., 2000), antidiabetic activity of root extracts of T. involucrata (Venkat Rao et al., 2007) were already reported. The present investigation is aimed at the phytochemical screening of chloroform extract of $T$. involcurata as well as 
characterization of compounds employing sophisticated techniques such as FT-IR and GC-MS. Light is also thrown on the chemotaxonomy of this species.

\section{MATERIALS AND METHODS \\ Plant collection}

Fresh plants of $T$. involucrata $L$ were collected in and around Trichy District, Tamil Nadu. Plant material was authenticated by the "The Flora of the Tamil Nadu Carnatic" (Mathew, 1981). A voucher specimen was deposited in the Rapinat Herbarium, St.Joseph's College, Trichy, Tamil Nadu.

\section{Preparation of chloroform extract}

The plant materials were shade dried and pulverized. Chloroform extract of the coarsely powdered material was prepared employing cold extraction method by soaking the plant material in chloroform for 48 hours and the extract was obtained by evaporating the solvent through distillation process.

\begin{tabular}{|c|c|}
\hline $\begin{array}{l}\text { Phytochemical } \\
\text { chromatography }\end{array}$ & screening \\
\hline
\end{tabular}
of drug powder as well as extract were carried out as per the methods and tests given by Dey and Sitaraman (1957) and Kokate (1995).

Column chromatography was carried out for the chloroform extract and about 68 fractions were collected.

\section{Thin Layer Chromatography (TLC)}

All the fractions collected through column chromatography of chloroform extract were subjected to TLC and the fractions from 22 to 27 were combined, which is dissolved in hexane as Sample 1, was subjected to TLC with mobile phase as chloroform with 2 drops of ethyl acetate and $50 \%$ sodium hydroxide as spray reagent.

\section{Fourier Transform -Infrared Spectroscopy (FT-IR)}

Fourier Transform - Infrared Spectroscopy (FT-IR) is a chemical analytical technique, which measures the infrared intensity (wave number) of light. Infrared spectroscopy detects the vibration characteristics of chemical functional groups present in a sample. The Sample 1 was subjected to FT-IR Spectroscopy to identify the chemical functional groups present in the sample.

\section{Gas Chromatography and Mass Spectroscopy (GC-MS)}

The sample is subjected to GC-MS to identify the compounds and also arrive at the structure of the compounds.

About $2 \mu \mathrm{l}$ of the sample was injected into the column as the helium gas moves at 1 $\mathrm{ml} / \mathrm{min}$ through the column and the gas chromatography condition was maintained between $100{ }^{\circ} \mathrm{C}-280{ }^{\circ} \mathrm{C}$ at $5{ }^{\circ} \mathrm{C} / \mathrm{min}$. The mass spectroscopy detected the compounds present in the sample using the above program by the formation of peaks. Using GC-MS library, the structures of the identified compounds were determined.

\section{RESULTS}

The preliminary phytochemical screening of the drug powder and the chloroform extract tested positively for terpenoids, flavones, quinones, alkaloids, sterols and proteins.

\section{TLC profile and infrared spectroscopy}

TLC profile showed pink spot at $R_{f}$ value 0.98 (Figure 1). IR Spectroscopy

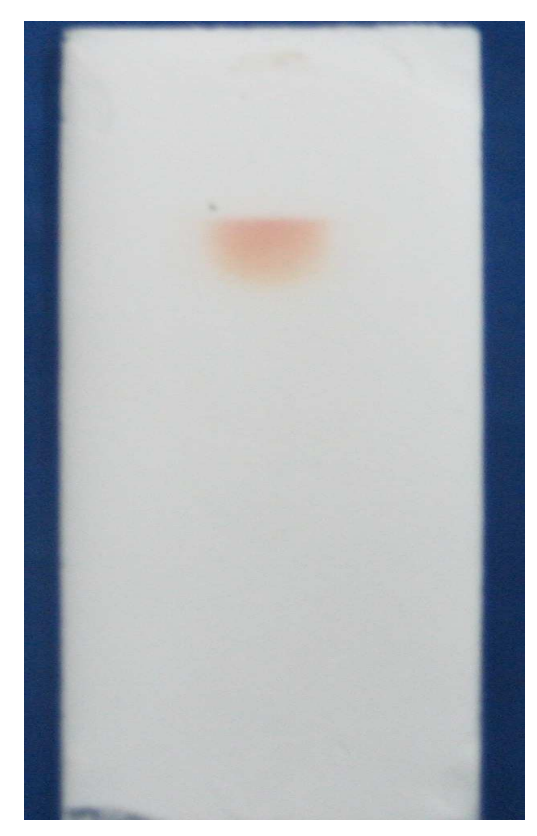

Figure 1: TLC profile. 
showed peaks at $3449.26,2925.55,2860.48$, 1713.56, 1453.60, 1381.05, 1263.10 and 1092.19 which were suggestive of the presence of $\mathrm{NH}$-Amine, $\mathrm{CH}-A$ lkane, $\mathrm{CH}$ Stretching, $\mathrm{C}=\mathrm{O}-$ Ketone, $\mathrm{C}=\mathrm{C}-\mathrm{Phenols}, \mathrm{C}-\mathrm{O}$ Alcohol, C-S-stretching respectively (Kalri, 1996) (Figure 2).

\section{Gas Chromatography and Mass} Spectroscopy

Through gas chromatography and mass spectroscopy, three compounds were identified as major compounds. They are ArTumerone; 9, 10 Anthrocenedione, 1, 8dihydroxy-3methyl; Friedelan-3-one (Figure 3-6; Table 1).

\section{DISCUSSION}

Chemotaxonomic studies on euphorbiaceae family

Euphorbiaceae is one of the ten dominant families occurring in southern peninsula and is grouped under the economically important plants.

This family is characterized taxonomically by the presence of milky sap and usually a single perianth and many stamens and chemically by the presence of alkaloids, tannins, flavones and terpenoids.

Chemotaxonomy studies commenced in 1950s, since then, an enormous amount of data has been done and the chemical data was further employed to solve various taxonomic problems, such as to strengthen the morphological separation of species, to interpret phylogeny, to analyse hybridization and to study the evolutionary significance of the plants with respect to the presence or absence of different compounds. The isolation of prenylcoumarin of chemotaxonomic significance from Murraya paniculata var. omphalocarpa was already reported (Takeshi et al., 1996). Jordanka et al. (2008) reported that sesquiterpene lactones were used as chemotaxonomic markers in genus Anthemis.

Following chemotaxonomic key proposed in the present work for Euphorbiaceae, Tragia was characterized by the presence of terpenoids. (Flow Chart 1). Thus Tragia typically fits in the Euphorbiaceae family and it was supported by the chemical evidences as reported in the present study.

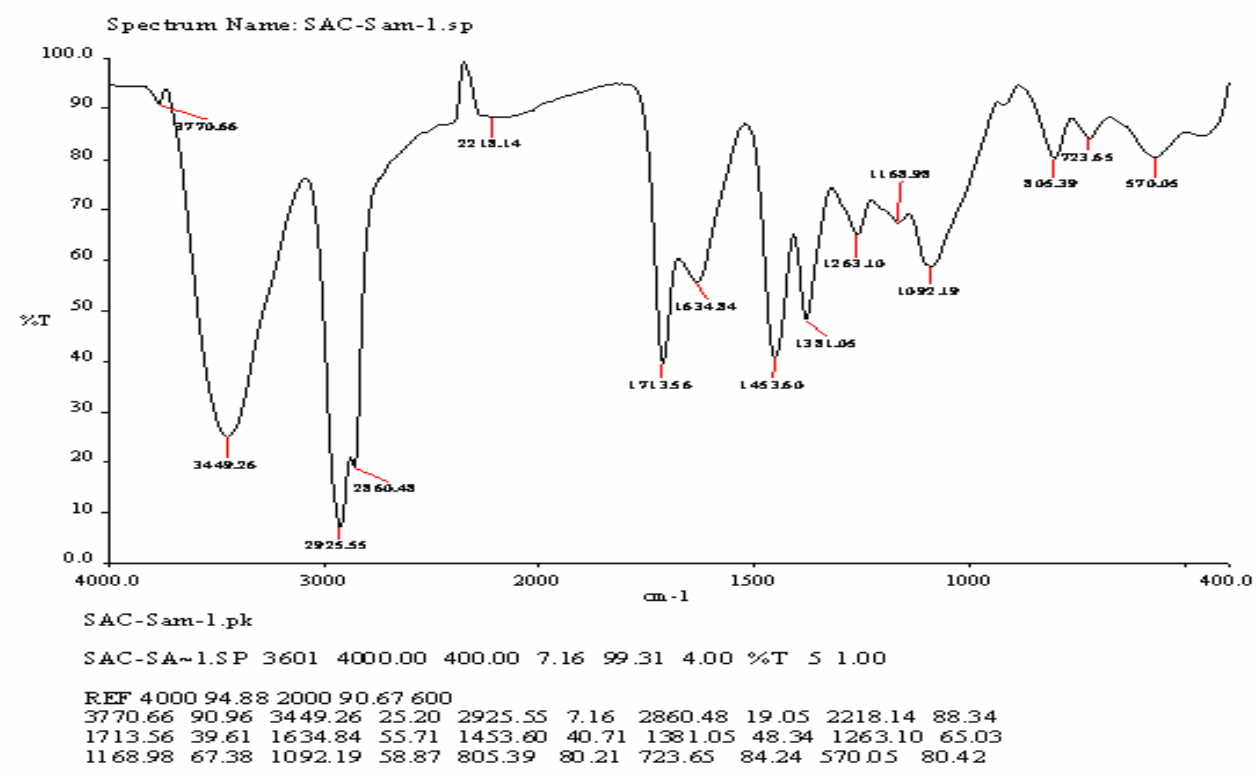

Figure 2: FT-IR spectrum. 


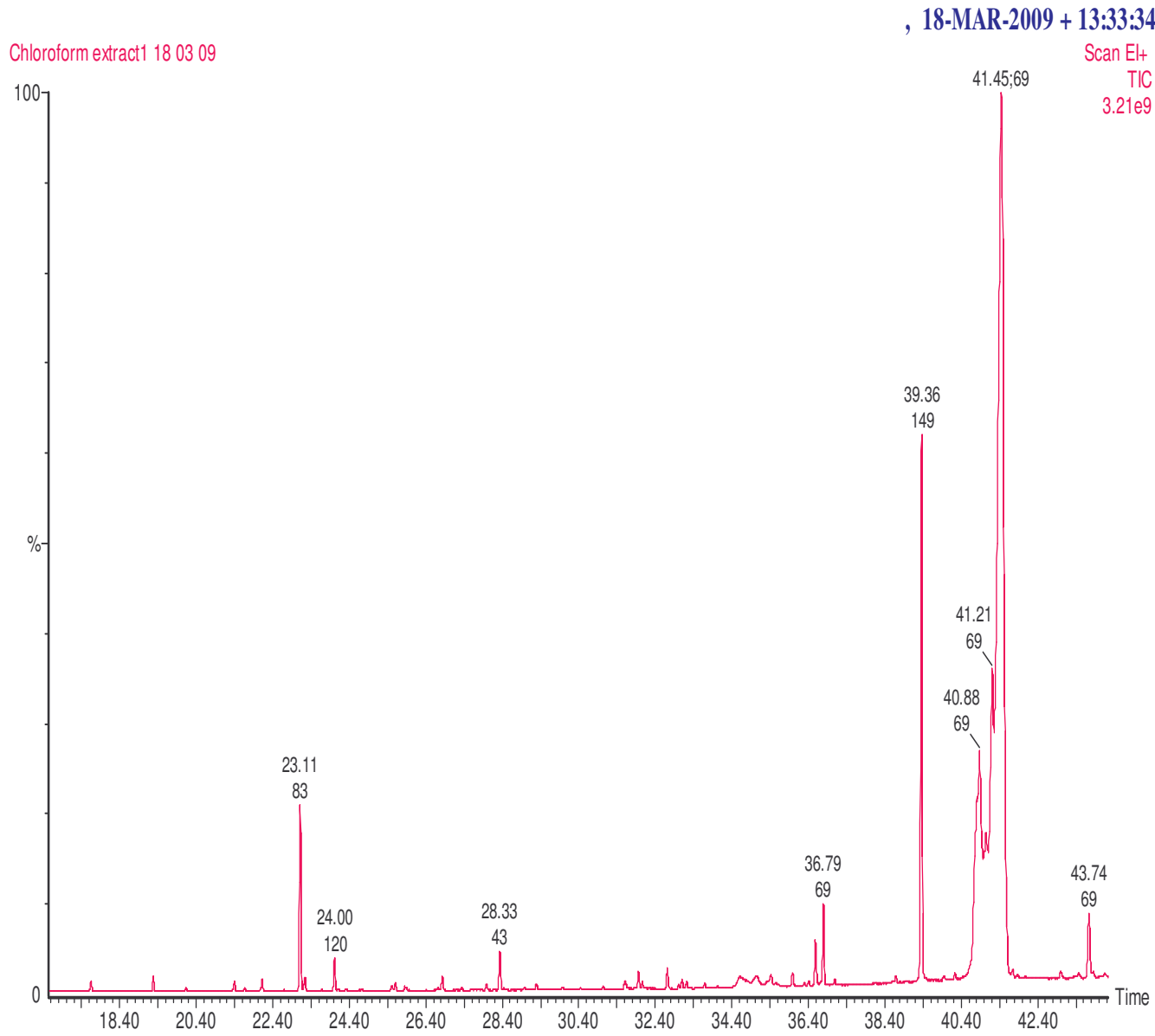

Figure 3: GC-MS profile.

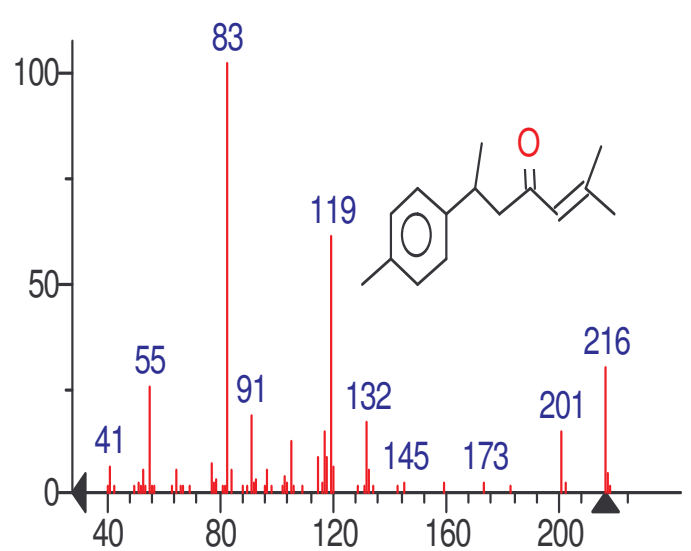

(mainlib) Ar-tumerone

Figure 4: Structure of Ar-Tumerone.

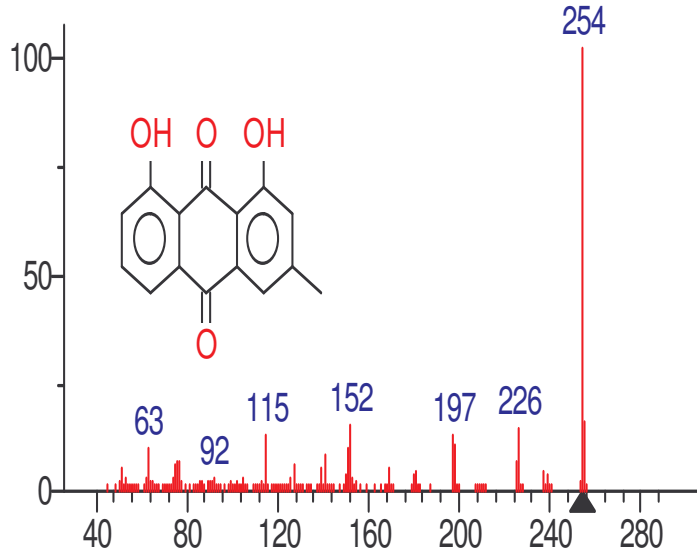

(replib) 9,10-Anthracenedione, 1,8-d ihydroxy-3-methyl-

Figure 5: Structure of 9, 10 Anthracenedione, 1,8-dihydroxy-3-methyl-. 


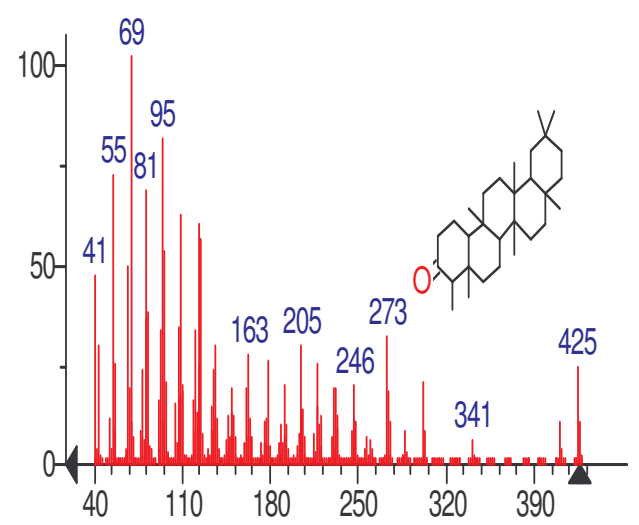

(replib) Friedelan-3-one
Table 1: List of compounds from Tragia involucrata Linn.

Figure 6: Structure of Friedelan- 3- one.

\begin{tabular}{llll}
$\begin{array}{l}\text { Ar-tumerone } \\
\text { Formula: } \mathrm{C}_{15} \mathrm{H}_{20} \mathrm{O},\end{array}$ & 23.11 & 28848364 & 4.3971 \\
MW: 216 & & & \\
\hline $\begin{array}{l}\text { 9,10-Anthracenedione, } \\
\text { 1,8-dihydroxy-3- }\end{array}$ & & & \\
methyl- & 36.58 & 7756223 & 1.1822 \\
Formula: $\mathrm{C}_{15} \mathrm{H}_{10} \mathrm{O}_{4}$, & & & \\
MW: 254 & & & \\
Friedelan-3-one & & & \\
Formula: $\mathrm{C}_{30} \mathrm{H}_{50} \mathrm{O}$, & 41.45 & 582884608 & 88.8434 \\
MW: 426 & & &
\end{tabular}

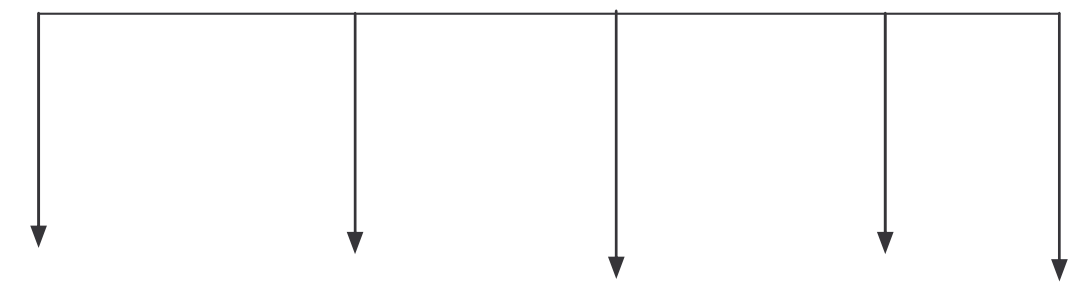

\begin{tabular}{|c|c|c|c|c|}
\hline ALKALOIDS & TERPENOIDS & TANNINS & GLYCOSIDES & FLAVONES \\
\hline Phyllanthus & Antidesma & Bridelia & Acetephilia & Hevea \\
\hline Fluggea & Glochidion & Emblica & Riccinus & ostodes \\
\hline Croton & Baccaurea & Breynia & Chrozophora & Tragia \\
\hline Jatropa & Putranjiva & Macaranga & & \\
\hline Manihot & Bischofia & Acalypha & & \\
\hline Baliospermum & Aleurites & Homonia & & \\
\hline Trewia & Mallotus & & & \\
\hline Excoecaria & Claoxylon & & & \\
\hline Sapium & Gelonium & & & \\
\hline Cleistanthus & Sapium & & & \\
\hline & Tragia & & & \\
\hline
\end{tabular}

Flow Chart 1: Chemotaxonomic tree of Euphorbiaceae. Major compounds reported: alkaloids, tannins, terpenoids, glycosides, flavones present. 


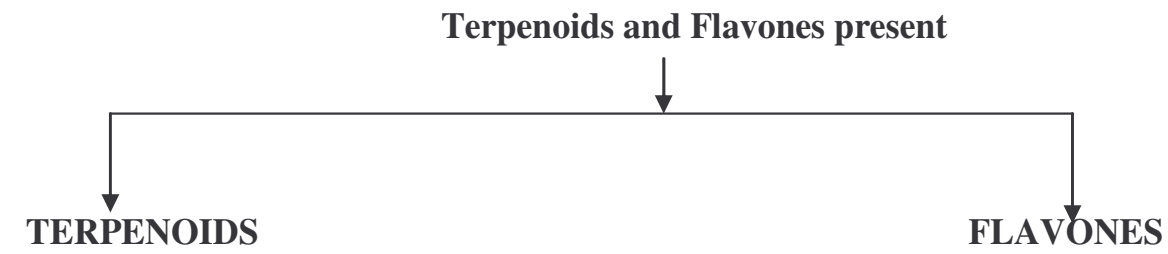

Antidesma

Hevea

Glochidion

ostodes

Baccaurea

Tragia

Putranjiva

Bischofia

Aleurites

Mallotus

Claoxylon

Gelonium

Sapium

Tragia

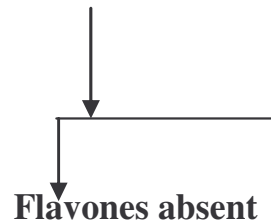

Antidesma

Flavones present

Glochidion

Tragia

Baccaurea

ostodes

Putranjiva

Bischofia

Aleurites

Mallotus

Claoxylon

Gelonium \& Sapium

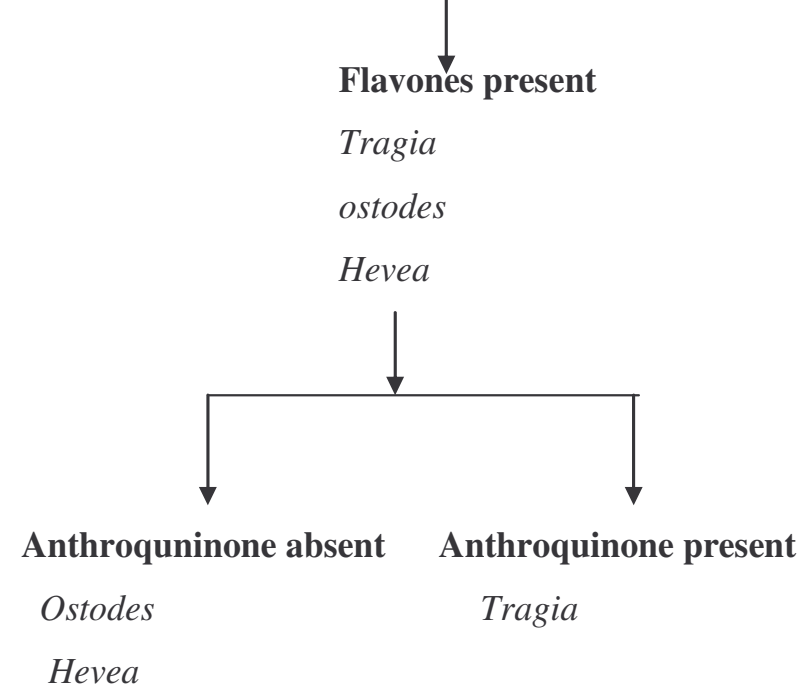

Flow Chart 2: Chemotaxonomic tree of Euphorbiaceae.

Chemical evidence determined in the present work was acids, terpenoids and tannins. Besides, unique compounds such as Ar-Tumerone; 9, 10 Anthrocenedione, 1, 8dihydroxy-3methyl; Friedelan-3-one were also identified. The chemical affinity of Tragia with Acalypha genera was also observed by the presence of anthroquinone in both genera. This terpenoids were not reported in other genera. 


\section{Conclusion}

To conclude, presence of terpenoids, alkaloids, quinones, sterols and tannins justifies the inclusion of Tragia in Euphorbiaceae family. Ar-tumerone reported in the present work suggests its affinity to Acalypha, a closely related genus of Tragia. Thus in present study $T$. involucrata L., a potential medicinal plant source rich in active principles and therapeutic potential was studied and reported from chemotaxonomic point of view. Light was also thrown on the importance of the salient chemical constituents in taxonomical studies as supporting evidences in assigning the systematic position of the plant.

\section{REFERENCES}

Alimuzzaman M, Muniruddin Ahamed. 2005. Analgesic activity of Tragia involucrata. Journal of Pharmaceutical Science, 4: 1.

Dey BB, Sitaraman MV. 1957. Laboratory Manual of Organic Chemistry. S. Viswanathan Publications: Madras.

Dhara AK, Suba V, Sen T, Pal S, Chaudhuri AK. 2000. Preliminary studies on the methanolic fraction of the root extract of Tragia involucrata Linn. Journal of Ethanopharmacology, 16: 326-330.

Jordanka D, Staneva, Milka N, Todorova, Ljuba N, Evstatieva. 2008. Sesquiterpene lactones as chemotaxonomic markers in genus Anthemis. Phytochemistry, 69(3): 607-618.

Kalri PS. 1996. Spectroscopy of Organic Compounds ( $2^{\text {nd }}$ edn). New Age International Publication: New Delhi.
Kokate CK. 1995. Practical Pharmacognosy (4th edn). Vallabh Prakashan: New Delhi.

Mathew KM. 1981. The flora of Tamil Nadu Carnatic. Rapinat Herbarium. $\mathrm{S}^{\mathrm{t}}$ Joseph College,Trichy.

Meyer JJ, Alfolayan AJ, Taylor MB, Eramas D. 1996. Antiviral activity of galangin from the aerial parts of Helichrysum aragonites. Journal of Ethnopharmacology, 56: 165-169.

Ramar PS, Ponnampalam GK, Peter H. Savarimuthu I. 2006. Purification of Antibacterial Agents from Tragia involucrata a popular tribal medicine for wound healing. Journal of Ethnopharmacology, 107: 99-106.

Ramar PS, Ponnampalam GK, Peter H, Maung T, Savarimuthu I. 2006. Effect of aqueous extract of Tragia involucrate Linn on acute and subacute Inflammation. Journal of Phytotherapy Research, 20: 310-312.

Takeshi K, Jin-Bin W, Feng-chi H. 1996. The isolation of a prenylcoumarin of chemotaxonomic significance from Murraya paniculata var. omphalocarpa. Phytochemistry, 43(1): 125-128.

Venkat Rao N, Benoy K, Hemamalini K, Shantakumar SM, Sathyanarayan S. 2007. Antidiabetic activity of root extracts of Tragia involucrata. Journal of Diabetica and Indian Tribal Medicine, 22: 232-244.

Zakaria M. 1991. Isolation and characterization of active compound from medicinal plants. Asian Pacific Journal of Pharmacology, 6: 15-20. 